Marquette University

e-Publications@Marquette

College of Nursing Faculty Research and

Publications

Nursing, College of

$12-1-2010$

Resilience in Family Members of Persons with Serious Mental Illness

Jaclene Zauszniewski

Case Western Reserve University

Abir K. Bekhet

Marquette University, abir.bekhet@marquette.edu

M. Jane Suresky

Case Western Reserve University

Accepted version. Nursing Clinics of North America, Vol. 45, No. 4 (December 2010). DOI. (C) 2010 Elsevier. Used with permission. 


\title{
Resilience in Family Members of Persons with Serious Mental Illness
}

\author{
Authors: Jaclene A. Zauszniewski, PhD, RN-BC ${ }^{a,}{ }^{*}$, Abir K. Bekhet, PhD, RN, HSMI ${ }^{b}, M$. \\ Jane Suresky, DNP, PMHCNS-BC ${ }^{a}$
}

\begin{abstract}
This integrative review summarizes current research on resilience in adult family members who have a relative with a diagnosed mental disorder that is considered serious. Within the context of resilience theory, studies identifying risk/vulnerability and positive/protective factors in family members are summarized, and studies examining seven indicators of resilience, including acceptance, hardiness, hope, mastery, self-efficacy, sense of coherence, and resourcefulness, are described. Implications for clinical practice and recommendations for future research are presented.
\end{abstract}

The most recent census in the United States found that nearly 58 million adults had a diagnosed mental disorder ${ }^{1}$ and $6 \%$ of these adults were diagnosed with a serious mental illness. ${ }^{2}$ Before deinstitutionalization and advances in the development of medications, persons with serious mental illnesses lived in institutions, apart from their families. Today, these individuals live in our communities. Although some adults with mental illness live independently, many live with family members, who care for them and help them manage daily activities. ${ }^{3,4}$ Even if they are not in the same household, family members are generally involved in their care and support. $^{5}$

Family members of persons with serious mental illness may endure considerable stress and burden that can compromise their own health and quality of life and impair the functioning of the family. However, if family members are resilient, they can overcome stress associated with providing care for a loved one with a mental illness, and preserve their own health and the health of their family. ${ }^{6,7}$ This integrative review summarizes current research on resilience in adult family members who have a relative with a serious mental disorder, including major depressive disorder, bipolar disorder, schizophrenia, and panic disorder. ${ }^{8}$ Although some studies have included children and young siblings providing care for a relative with a mental illness, this review focuses on family members who are adults.

\section{Resilience}

1 Zauszniewski, Bekhet \& Suresy 
Early writings on resilience came from researchers who focused on its development in children and adolescents. ${ }^{9,10}$ More recently, there has been an increased interest in resilience in adults ${ }^{11}$ and families. ${ }^{12}$ The concept of resilience was described by Rutter ${ }^{13}$ as "relative resistance to psychosocial risk experiences" (p. 119), and by Luthar and colleagues ${ }^{14}$ as "a dynamic process encompassing positive adaptation within the context of significant adversity." Richardson ${ }^{15}$ defined resilience as "the process of coping with adversity, change, or opportunity in a manner that results in the identification, fortification, and enrichment of resilient qualities or protective factors" (p. 308). Definitions of resilience in caregivers vary, ${ }^{16}$ but they all share the characteristic of overcoming adversity to not only survive the day-to-day burden of caring for a family member who is mentally ill, but to thrive; that is, to grow into a stronger, more flexible, and healthier person. ${ }^{17}$ Resilience theory focuses on the strengths possessed by individuals or families that enable them to overcome adversity. The central constructs of resilience theory are risk or vulnerability factors, positive or protective factors, indicators of resilience, and outcomes of resilience.

\section{Risk/Vulnerability Factors}

Risk factors have been conceptualized as events or conditions associated with adversity, or factors that reduce one's ability to resist stressors or overcome adversity. ${ }^{11}$ Vulnerability factors include traits, genetic predispositions, or environmental and biologic deficits. Potential risk factors in caring for a family member with a serious mental illness include caregiver strain, feelings of stigma, client dependence, and family disruption; together, these factors can seriously compromise the caregiver's resilience. ${ }^{18}$ Table 1 lists examples of risk or vulnerability factors that were identified in studies of family members of adults with serious mental illness.

Having a family member with a mental illness puts family members and the family unit at risk for experiencing negative outcome in terms of the physical and mental health of individual family members and the functioning of the family. ${ }^{19,20}$ When the mentally ill family member is living in the same household, this may put relatives at greater risk for compromised health. 19,20 And the risk for poor health may increase even more when the mentally ill person requires ongoing supervision or direct personal care. ${ }^{21}$ The lack of available, accessible, or affordable mental health services for families with a person with mental illness has been identified as a risk factor in several studies. ${ }^{21}$

Some demographic features of family caregivers may increase their vulnerability to compromised health, including age ${ }^{22,23}$ and level of education. ${ }^{23}$ The studies suggested that older 2 Zauszniewski, Bekhet \& Suresy 
family members and those who have less education may be more prone to health problems and disruptions in family functioning.

Family caregivers who appraise their situation as threatening are believed to be at greater risk. ${ }^{24}$ They may perceive caregiving as burdensome or stressful, ${ }^{25-27}$ and they report greater feelings of strain, ${ }^{27}$ more stressful life events, ${ }^{28}$ and greater disruption in family functioning. ${ }^{27}$ Perlick and colleagues ${ }^{25}$ found a high use of avoidance coping strategies by family members of persons with mental illness. Although avoidance coping may be a less-than-optimal method for coping, it is possible that this coping method may also be protective; thus, risk factors in one context may be protective in another..$^{11,13,29}$

\section{Protective/Positive Factors}

According to Rutter, ${ }^{30}$ protective factors reduce the effect of risk, decrease negative reactions to risk, promote resilience, and create opportunities for family caregivers, and include strategies for maintaining a positive success. Protective factors identified in studies of family members of adults with mental illness reflect their appraisal of the caregiving situation itself and their personal beliefs. A positive appraisal of the situation ${ }^{24}$ and positive cognitions ${ }^{18}$ have both been linked with greater resilience and better health outcomes. In addition, Murray-Swank and colleagues $^{22}$ found that personal religiosity helped family members of persons with mental illness adapt to the situation. Although positive appraisal, positive cognitions, and personal religiosity are intrapersonal factors that provide protection for family member of persons with mental illness, interpersonal and extrapersonal protective factors have also been identified.

Social support ${ }^{23}$ and psychoeducation programs for family members ${ }^{31-33}$ have been found to have positive effects on resilience and health outcomes for individuals and the family unit. Also, the duration of the caregiving experience, which is closely related to increasing age of the mentally ill care recipient, has been associated with resilience and quality of life in family members of adults with serious mental illness. ${ }^{34}$

\section{Resilience In Family Caregivers}

Only 3 studies of resilience in family members of persons with mental illness have been published, and all 3 were conducted more than a decade ago. Enns and colleagues ${ }^{35}$ collected data on family resources, perceptions, and overall adaptation of 111 family members of adults admitted to a psychiatric hospital to identify factors that might contribute to resilience in family members. The data collected on major study variables were compared with averages on similar 
measures in the general population, and family members in the study were found to be similar to the general population on measures of health $(p$-norms $=.546)$ and well-being $(p$-norms $=.018)$, role performance $(p-n o r m s=.103)$, task accomplishment $(p-n o r m s=.424)$, and values and norms ( $p$-norms $=.308$ ). They had significantly less perceived social support, esteem, and communication, and were less likely to seek spiritual support than the general population. However, they were more likely to acquire social support and to mobilize the immediate family, and they had higher scores on affective expression, communication, and perceived control.

Marsh and colleagues ${ }^{36}$ conducted a national survey to investigate the effects of resilience among family members of people with mental illness. The 131 family members in the sample were mothers, fathers, wives, husbands, sisters, brothers, daughters, sons, and extended family members. Family members were asked to identify strengths within themselves, their family, or their mentally ill family member who they believed were developed in relation to their family member's mental illness. Personal resilience was reported most frequently (by $99 \%$ of participants), followed by family resilience (88\%) and resilience in the mentally ill family member (76\%). Mannion, ${ }^{37}$ who did a follow-up analysis of the data from that survey, found that most spouses (83\%) described a process of adaptation and recovery and cited personal resilience as a major factor in facilitating positive changes. Personal resilience was described more strongly than family resilience or resilience in the mentally ill family member.

These studies of resilience were all conducted in the 1990s. No recent studies have specifically examined resilience in family members of persons with serious mental illness. However, recent research has identified several strengths, characteristics, qualities, and virtues as indicators of resilience, $6,15,17$ including acceptance, hardiness, hope, mastery, self-efficacy, sense of coherence, and resourcefulness. Studies that examined these resilience indicators in family members of persons with mental illness are reviewed later in this article.

\section{Acceptance}

Acceptance has been defined as a willingness to fully experience internal events, including thoughts, feelings, memories, and sensations. ${ }^{38}$ It refers to an active process of understanding and having a sense of obligation and resignation to an unchangeable situation. ${ }^{39}$ Christensen and Jacobson ${ }^{40}$ defined acceptance as the ability to tolerate what might be regarded as an unpleasant behavior of a relative with mental illness, with some understanding of the deeper meaning of that behavior and an appreciation of its value and importance.

Four studies of family members of adults with mental illness have suggested that acceptance of the caregiving situation and the relative's diagnosis of mental illness is an 
indicator of resilience. In a study of 80 family members conducted in Ghana, Quinn ${ }^{41}$ found that, in rural areas, families were more accepting of the mental illness and therefore more supportive of their loved ones. In a qualitative study conducted in Thailand, 17 Buddhist family members of persons with mental illness shared their beliefs and perspectives on their experiences with their mentally ill family member. ${ }^{39}$ The themes they identified included management, compassion, and acceptance. Fortune and colleagues,$^{24}$ who examined relationships among perceptions of their loved one's psychosis, coping strategies, cognitive appraisals, and distress with 42 relatives of adults with schizophrenia, found that family members who expressed greater acceptance of their relative's psychosis, its severity, and consequences, experienced less distress $(r=-0.66$, $p<.001)$. In addition, acceptance, along with positive reframing and a lower tendency toward self-blame, was found to mediate the effects of perceptions of their relative's illness on their distress.

Only 1 study has examined the needs of caregivers of people with mental illness in the United States. This intervention study by Eisner and Johnson ${ }^{42}$ examined the effects of a psychoeducation program for 28 families who had a family member diagnosed with bipolar disorder. Their intervention also taught acceptance to the family members to decrease their anger and minimize self-blame. One week after the intervention, the family members were found to have more knowledge about their relative's illness, but their anger and self-blame remained unchanged. However, the results cannot be generalized because of the small sample size, and because baseline scores on criticism and anger were low. The study used self-report measures, and the length of the period was only 1 week, making it difficult to practice or implement what had been learned. Despite its limitations, this intervention study did address the needs of family members of persons with mental illness. Given the importance of the topic, more intervention studies are needed.

\section{Hardiness}

Hardiness was defined by Kobasa ${ }^{43}$ as a personality characteristic consisting of 3 interrelated concepts: control, commitment, and challenge. However, others have said that hardiness involves cognitive and behavioral flexibility, motivation to follow through with plans, and endurance when faced with adversity. ${ }^{44}$ In caregivers, hardiness has been found to minimize the burden of caregiving, ${ }^{45}$ and enable caregivers to appraise the caregiving situation more positively ${ }^{46}$ and use problem-focused coping methods, including help-seeking strategies. ${ }^{47}$

Two studies have examined hardiness in family members of persons with mental illness. Greef and colleagues ${ }^{48}$ studied 30 families of mentally ill young adults (average age 24 years) in 
Belgium, most of whom were diagnosed with schizophrenia or other psychosis or mood or anxiety disorder. Of 12 potential resilience indicators examined in that study, hardiness was found to have the strongest correlation with family adaptation $(r=0.63 ; p<.01)$. Also, Han and colleagues, ${ }^{49}$ who collected data from 365 Korean families providing care for a relative with a chronic mental illness, found a significant correlation between hardiness and family functioning $(r$ $=0.51, p<.001)$.

Neither of the 2 studies examined interventions; clearly intervention studies are needed to test the effects of programs to improve functioning in families with a relative with chronic mental illness. Large representative samples are also needed, as well as more focused homogeneous samples in terms of type of mental illness, length of illness, and age of the mentally ill person to be able to generalize the findings.

\section{Mastery}

Mastery has been defined as the extent to which individuals believe they have control over what happens in their life. ${ }^{50}$ Thus, it can be conceptualized as a dimension of coping with stress that reflects a sense of personal control over potentially adverse circumstances. A sense of mastery has been identified as a resource that may facilitate family adaptation to mental illness. ${ }^{51}$ In family caregivers, greater mastery has been associated with lower caregiver burden and psychological distress and a greater sense of competence in the caregiving role. ${ }^{25,52}$

Five studies of family members of persons with mental illness have examined mastery, which may be viewed as an indicator of resilience. Murray-Swank and colleagues ${ }^{22}$ studied 83 caregivers of persons with serious mental illness to examine whether religiosity was associated with psychosocial adjustment and caregiver burden. The findings indicated that younger age and greater religiosity were both associated with mastery $(r=-0.28, p=.009$ and $r=0.26, p=.017)$.

Perlick and colleagues ${ }^{25}$ studied 500 caregivers of adults with bipolar disorder to identify caregivers at risk for poor health in relation to caregiving and stress. The caregivers comprised 3 groups: those who were considered burdened, those considered effective, and those considered stigmatized. Those who were burdened experienced poorer health outcomes than the other 2 groups. They also reported lower mastery than the other groups $\left(F_{1,2}=47.97, p<.001\right)$.

Lau and Pang, ${ }^{53}$ who examined how 129 relatives providing care for persons with major psychiatric illnesses appraised their caregiving, found that a better sense of mastery was associated with less negative appraisal $(r=-0.24, p=.03)$; however, no relationship was found between mastery and positive appraisal of caregiving itself. Rose and colleagues ${ }^{52}$ evaluated feelings of burden and sense of mastery of 30 family members of relatives with mental illness. No

\section{Zauszniewski, Bekhet \& Suresy}


significant association was found between caregiver burden and mastery. The researchers explained that the lack of significance may have resulted from the mastery scale's inability to capture perceived lack of control among family members.

Pollio and colleagues ${ }^{33}$ compared the effects of a psychoeducation group for 9 family members of adults with mental illness to usual services for family members. The 7 family members who completed the intervention showed significant improvements on 4 of 5 items measuring knowledge and mastery, and scores increased on the specific item that reflected feeling in control, although not significantly. Although these findings should be interpreted with caution, given the small sample, the results suggest that psychoeducation enhances a sense of mastery among family caregivers of persons with mental disorders. Future intervention research should use larger samples and analytical models with behavioral measures for both families and their ill members. Furthermore, outcomes should be measured immediately after the intervention, and 3 months, 6 months, and 1 year after the intervention to indicate whether mastery can be maintained over time.

\section{Hope}

Hope has been characterized as multidimensional and dynamic, with elements of confidence, but uncertain expectation of a positive outcome ${ }^{54}$ Hope is created from memories and influenced by relationships with others; it promotes forward movement and provides new insights and a sense of purpose.$^{55}$ Hope has been identified as an integral part of family members' ability to cope with mental illness in a family member. ${ }^{56}$

Seven studies have examined hope or optimism in family members of adults with mental illness. Bland and Darlington, ${ }^{56}$ who conducted in-depth interviews with 16 family members in Australia to explore the meaning and importance of hope, found that hopefulness was an integral part of the coping process used by the family members. Karp and Tanarugsachock ${ }^{57}$ conducted in-depth interviews with 50 family members of adults with depression, bipolar disorder, or schizophrenia to explore how family members managed their emotions during the course of the family member's mental illness. They found that it was at the point of diagnosis that feelings of hope were provoked in family members.

Using individual interviews and focus groups, Stjernswärd and Ostman ${ }^{20}$ explored the experiences of 18 family members living with an individual with depression. The family members described hope as a motivating force for finding effective treatment, a trustworthy physician, a meaningful and productive future, and improved quality of life for both the mentally ill family member and themselves. Tweedell and colleagues ${ }^{58}$ studied the experiences of 8 family 
members with a chronically mentally ill relative. During interviews conducted 5 times in a 1-year period, family members described hopes and fears associated with interpersonal relationships with their family member. They were unanimous in hoping their relatives would gain relief from suffering psychotic symptoms, return to their former selves, be independent in caring for themselves, and live a worthwhile and productive life. They also expressed cautious optimism that treatment would last, and some worried about losing hope for treatment, symptom management, and improved quality of life for their family member.

Pickett-Schenk and colleagues ${ }^{21}$ studied 424 families of persons with schizophrenia who took part in an intervention designed to instill hope by providing education and support. Data were collected before the intervention and at 3 and 6 months following the program. At 3 months after the intervention, greater satisfaction with the education and support components of the intervention program predicted increased knowledge of the causes and treatment of mental illness $(\beta=0.29, p<.001$ and $\beta=0.21, p<.001)$, greater understanding of mental health services $(\beta=0.25, p<.001$ and $\beta=0.34, p<.001)$, and improved morale $(\beta=0.19, p<.001$ and $\beta=0.18, p<.001$ ). Some effects of satisfaction persisted at 6 months, but the effects on morale and understanding of mental heath services were not found 6 months after the intervention.

Pickett-Schenk and colleagues ${ }^{19}$ also examined the effectiveness of the same intervention for 462 family members of adults with schizophrenia. As in the previous study, the intervention included education about the causes and treatment of mental illness, problem-solving and communication skills training, and family support. Outcomes were evaluated before intervention and at 3 and 6 months after the intervention. Family members in the intervention group reported better psychological well-being than those in a waiting list control group as indicated by fewer depressive symptoms $(\beta=-1.64, p=.04)$, greater emotional role functioning ( $\beta=5.69, p=.03$ ) and vitality $(\beta=3.57, p=.04)$, and less negative views toward relationships with their mentally ill family member $(\beta=-0.73, p<.01)$. These effects were maintained over time.

In a follow-up study, Pickett-Schenk and colleagues ${ }^{59}$ examined the effects of the same intervention on family members' knowledge of causes and treatment of schizophrenia, problem-solving skills, and need for information. Those in the intervention group reported greater gains in knowledge than a waiting list control group $(\beta=0.84, p<.01)$, fewer needs for information on coping with positive and negative symptoms of their family member's illness ( $\beta=$ $-0.63, p<.05$ and $\beta 5-0.80, p<.001$, respectively), and greater gains in problem management $(\beta=-1.00, p<.001)$, basic facts about mental illness and its treatment $(\beta=-0.73, p<.01)$, and

\section{Zauszniewski, Bekhet \& Suresy}


community resources $(\beta=-0.07, p<.05)$. The effects were maintained over time.

Of these 7 studies, only 1 was a randomized controlled trial ${ }^{19}$ and the randomized controlled trial had some limitations, including a possible placebo effect and use of self-reported data, making it difficult to determine whether the intervention brought about actual improvements in the family members' relationships with their mentally ill relatives. ${ }^{19}$ Intervention studies that include behavioral observations rather than self-report are needed.

\section{Self-Efficacy}

Self-efficacy refers to an individual's confidence in dealing with challenging and stressful encounters, ${ }^{60}$ or the self-evaluation of one's capacity for performing an activity or task to achieve a specific goal. ${ }^{61}$ In family caregivers of persons with mental illness, greater self-efficacy has been linked with better management of behavioral problems in care receivers, less perceived stress, and lower subjective burden. ${ }^{6}$

Two studies have examined self-efficacy of family members of adults with schizophrenia. Both studies involved Chinese family members. Cheng and Chan ${ }^{32}$ evaluated the effectiveness of a psychoeducation program with 64 family caregivers recruited from a mental hospital in Hong Kong. Those in the psychoeducation group improved more in self-efficacy than a group receiving routine care $(t=-7.16, p<.01)$. The effectiveness of the psychoeducation program was then tested in another study of 73 Chinese family caregivers of persons with schizophrenia ${ }^{31}$; this study also examined longer-term effects. Postintervention effects on self-efficacy were similar to those in the first study and these effects were sustained at 6 months, but not at 12 months, indicating a need for continued intervention to promote self-efficacy.

Although both studies provided promising results, they had several limitations. For example, the measures used were self-reported, and the mentally ill persons were primarily men, although caregivers were women. ${ }^{31}$ Also, the studies included only family members who were willing to participate, so this group might have had more motivation to change, leading to positive outcomes. $^{32}$

\section{Sense of Coherence}

A sense of coherence has been defined as a global orientation toward life that involves cognitive, behavioral, and motivational elements, and is expressed in the belief that the world is comprehensible, manageable, and meaningful. ${ }^{62}$ Family sense of coherence refers to the belief of family members that the internal and external environments are structured and predictable and that resources are available; they perceive life and their situation as a meaningful challenge and consider that they can exert an influence on the course of events. ${ }^{48}$

\section{Zauszniewski, Bekhet \& Suresy}


Five studies have evaluated sense of coherence in family members of adults with mental illness. Han and colleagues, ${ }^{49}$ who examined the influence of a sense of coherence on family functioning in 365 Korean families providing care for a relative with a chronic mental illness, found a significant positive correlation between sense of coherence and family functioning ( $r=$

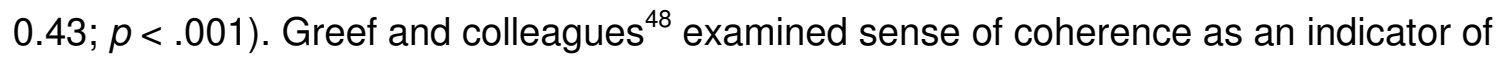
adaptation in 30 families of mentally ill persons in Belgium. Hardiness showed the strongest correlation with sense of coherence $(r=0.63 ; p<.01)$. In a study of 556 Thai family caregivers of adults with schizophrenia, Pipatananond and colleagues ${ }^{23}$ found that sense of coherence was influenced by education $(Y=0.29, p<.001)$, income $(Y=0.28, p<.001)$, social support $(\gamma=0.20$, $p<.001)$, and perceived seriousness of illness $(\gamma=0.23, p<.001)$, and sense of coherence had a direct negative effect on caregiver burden $(\beta=0.16, p<.001) .{ }^{23}$

In a study of 60 American women who were family members of adults with serious mental illness, Suresky and colleagues ${ }^{26}$ found that caregiver burden had a negative effect on sense of coherence $(\beta=-0.33 ; p<.01)$, although sense of coherence accounted for $41 \%$ of the variance in quality of life and partially mediated the effects of caregiver burden on quality of life. ${ }^{26}$ In a follow-up study on the same women, Zauszniewski and colleagues ${ }^{18}$ found that the effects of caregiver burden on sense of coherence were mediated by positive cognitions, which served as protective factors.

No studies have evaluated interventions for sense of coherence in family members of adults with mental illness, and the studies reviewed had some limitations. Most were either cross-sectional $\left.\right|^{23,48,49}$ or secondary analyses ${ }^{18,26}$ and, therefore, it is difficult to assess changes in study variables over time. Convenience sampling limits the generalizability of the findings, and the samples were heterogeneous in type of mental illness, length of illness, single parent or intact family, and age of the mentally ill family member. ${ }^{48}$ Also, given the small samples, caution must be used in drawing conclusions from the findings. ${ }^{18,26,48}$

\section{Resourcefulness}

Resourcefulness may be defined as cognitive and behavioral skills that are used to prevent potentially negative effects of thoughts, feelings, or sensations on the performance of daily activities ${ }^{63}$ and to obtain assistance from others when unable to function independently. ${ }^{64}$ Personal and social resourcefulness skills are complementary, can fluctuate over time, and are equally important for optimal quality of life. ${ }^{65}$

Four studies have examined resourcefulness in family caregivers of persons with serious mental illness. Wang and colleagues ${ }^{28}$ examined the effects of resourcefulness on stressful life 10 Zauszniewski, Bekhet \& Suresy 
events, psychiatric care activities, and the burden faced by 81 family caregivers of schizophrenic adolescents. The study found that $24.5 \%$ of the variance $\left(F_{5,75}=6.20, p<.001\right)$ in caregiver burden was explained by psychiatric care activities and the interaction of stressful life events and resourcefulness, indicating that resourcefulness moderated the adverse effects of stressful life events on caregiver burden.

Zauszniewski and colleagues ${ }^{34}$ studied 60 women who were family members of adults diagnosed with schizophrenia, bipolar disorder, depression, or a panic anxiety disorder to identify factors that might affect family members' resourcefulness. Increasing age of the mentally ill person and longer time since diagnosis were associated with greater personal resourcefulness $(r$ $=0.32, p<.01$ and $r=0.35, p<.01$, respectively). The women who were caregivers of adults with schizophrenia had greater personal and resourcefulness $\left(t_{1,52}=4.19, p<.01\right.$ and $t_{1,52}=2.62$, $p<.01$, respectively) than women who had a family member with bipolar disorder. Sisters of mentally ill persons reported more social resourcefulness than did mothers, daughters, or wives $\left(F_{2,59}=-3.16, p<.05\right)$, but there were no significant differences in personal resourcefulness.

In a follow-up study of the same women, Zauszniewski and colleagues ${ }^{27}$ found that African American and white women reported similar resourcefulness skills. However, in African Americans, greater caregiver burden was associated with lower resourcefulness $(r=-0.38, p$ $<.0010)$ and lower resourcefulness correlated with poorer mental health $(r=0.53, p<.001)$, suggesting that resourcefulness may mediate the adverse effects of caregiver burden on mental health. Another follow-up study by Zauszniewski and colleagues ${ }^{18}$ focused on the mediating role played by positive cognitions, conceptualized as a protective factor, on the relationship between caregiver burden and resourcefulness. The findings from that study provide support for resilience theory in that positive cognitions mediated the effects of caregiver burden on resourcefulness, an indicator of resilience.

All 4 of these studies were cross-sectional or secondary analyses, and none included an intervention. The studies also had some limitations, such as convenience samples, cross-sectional design, and small sample sizes. ${ }^{18,27,34}$ Longitudinal studies of larger and more diverse samples of family members of mentally ill persons, including men and persons from racial/ethnic minorities, are recommended. Intervention studies that teach cognitive behavioral self-help and help-seeking skills are also needed. Addressing the needs of family members of adolescents with serious mental illness is important; thus, intervention studies are needed for this vulnerable population. 


\section{Outcomes of Resilience}

Resilience and resilience indicators have been linked with several positive health outcomes for individuals and families. ${ }^{17}$ In the studies of family members of adults with mental illness included in this review, resilience indicators were found to be associated with and, in some cases, to affect or predict outcomes that indicate mental and physical health and quality of life in individual family members and optimal family functioning.

On the individual level, resilience indicators have been linked with decreased caregiver burden in family members of persons with mental illness. ${ }^{23,28}$ In addition, decreased levels of expressed emotion, defined as a critical, hostile, or overinvolved attitude toward a relative with mental illness, have been associated with greater resilience in family members of persons with mental illness. ${ }^{42}$ Other outcomes of resilience indicators found in studies of family members include better morale,${ }^{21}$ greater psychological well-being, ${ }^{19,24}$ and improved knowledge and understanding of their family member's diagnosis. ${ }^{21,59}$ Two studies of family members found that enhanced quality of life was associated with indicators of resilience. ${ }^{26,27}$ Greater resilience may also be linked with improvement in family members' relationships with their relative with a psychiatric diagnosis. ${ }^{19}$ Resilience has also been associated with greater family adaptation ${ }^{48}$ and improvement in family functioning. ${ }^{49}$

\section{Summary}

Although resilience has been examined in studies of family caregivers, few studies have included family members of persons with serious mental illness. However, many researchers have examined characteristics of family members of persons with mental illness that may be considered indicators of resilience, including acceptance, hardiness, hope, mastery, self-efficacy, sense of coherence, and resourcefulness. The research has consistently shown that family members who possess these positive characteristics are better able to manage and overcome adversity associated with caring for a family member diagnosed with a mental illness. Thus, enhancement of the resilience of family members of persons with serious mental illness contributes to both their own well-being and the well-being of those for whom they provide care.

The findings from the studies reviewed here provide beginning evidence of the importance of focusing nursing interventions on supporting and enhancing the resilience of family members of individuals with mental illness. However, additional studies to develop and test interventions for enhancing the characteristics constituting resilience in these family members are needed. Longitudinal studies that measure outcomes immediately after the

\section{Zauszniewski, Bekhet \& Suresy}


intervention and at 3 months, 6 months, and 1 year after the intervention would provide a picture of how resilience indicators can be enhanced and maintained. Also, intervention studies that include behavioral observation, rather than relying solely on self-report, are needed. The evidence that emerges from testing well-developed interventions can inform clinical practice and enrich psychiatric nurses' ability to provide quality care for patients and their families.

Advanced practice nurses (APNs) need to take a focused family therapy approach to manage stress and disruption in the family environment, to build the family's resilience and contribute to improvement in quality of life for the family and the person who is mentally ill. Assessing family members' level of hardiness, sense of coherence, hope, and resourcefulness using standardized measures at the start of a treatment plan for family therapy could provide baseline data and direction for therapy. Assisting the family to gain knowledge of the mental illness and associated behaviors would facilitate understanding of the patient's situation. In addition to using a cognitive approach to therapy, APNs might suggest adjunct therapies for individual family members. For example, yoga has been found to be beneficial in reducing anxiety and depression, acupuncture is used to treat stress, and self-hypnosis provides a feeling of letting go of internal pressure and discomfort. At the conclusion of therapy, hardiness, sense of coherence, hope, and resourcefulness should be measured again and compared with baseline results to provide further direction for therapy.

The information derived from the current review can be used by psychiatric nurses to plan primary, secondary, and tertiary prevention strategies to help caregivers of persons with mental illness regain, attain, or maintain optimal wellness. Assessing an individual's attitude toward mental illness, and his or her strengths and concerns, is vital to facilitate adjustment. Secondary prevention should be implemented when stress symptoms have already developed. Secondary prevention should encompass interventions to increase resilience for those with stress as a result of their caregiving. Tertiary prevention would help caregivers to use all existing internal and external resources to prevent further stress and maintain optimal wellness.

\section{Notes}

${ }^{a}$ Frances Payne Bolton School of Nursing, Case Western Reserve University, 10900 Euclid Avenue, Cleveland, OH 44106-4904, USA

${ }^{\mathrm{b}}$ Marquette University College of Nursing, 530 North 16th Street, Milwaukee, WI 53233, USA

*Corresponding author. E-mail address: jaz@case.edu 


\section{References}

1. US Census Bureau. Population estimates by demographic characteristics. Table 2: annual estimates of the population by selected age groups and sex for the United States: April 1, 2000 to July 1, 2004. US Census Bureau: Population Division 2005 (NC-EST2004-02).

2. Kessler RC, Chiu WT, Demler O, et al. Prevalence, severity, and comorbidity of 12-month DSM-IV disorders in the National Comorbidity Survey replication. Arch Gen Psychiatry 2005;62:617-27.

3. Kohn-Wood LP, Wilson MN. The context of caretaking in rural areas: family factors influencing the level of functioning of seriously mentally ill patients living at home. Am J Community Psychol 2005;36(1/2):1-13.

4. Wynaden D, Ladzinski U, Lapsley J, et al. The caregiving experience: how much do health professionals understand? Collegian 2006;13(3):6-10.

5. Lively S, Friedrich RM, Rubenstein L. The effect of disturbing illness behaviors on siblings of persons with schizophrenia. J Am Psychiatr Nurses Assoc 2004;10(5): 222-32.

6. Saunders JC. Families living with severe mental illness: a literature review. Issues Ment Health Nurs 2003;24(2):175-98.

7. Walton-Moss B, Gerson L, Rose L. Effects of mental illness on family quality of life. Issues Ment Health Nurs 2005;26:627-42.

8. Bye L, Partridge J. State level classification of serious mental illness: a case for a more uniform standard. J Health Soc Policy 2004;19(2):1-29.

9. Garmezy N, Rutter M. Stress, coping, and development in children. New York: McGraw-Hill; 1983.

10. Werner EE, Smith RS. Overcoming the odds: high risk children from birth to adulthood. Ithaca (NY): Cornell University Press; 1992.

11. Smith-Osborne A. Life span and resiliency theory: a critical review. Adv Soc Work 2007;18(1):152-68.

12. McCubbin MA, McCubbin HI. Resiliency in families: a conceptual model of family adjustment and adaptation in response to stress and crises. In: McCubbin HI, Thompson Al, McCubbin MA, editors. Family assessment: resiliency, coping, and adaptation-Inventories for research and practice. Madison (WI): University of Wisconsin System; 1996. p. 1-64.

13. Rutter M. Resilience concepts and findings: implications for family therapy. J Fam Ther 1999;2:119-44.

14. Luthar S, Cicchetti D, Becker B. The construct of resilience: a critical evaluation and

14 Zauszniewski, Bekhet \& Suresy 
guidelines for future work. Child Dev 2000;71:543-62.

15. Richardson GE. The metatheory of resilience and resiliency. J Clin Psychol 2002; 58(3):307-21.

16. Gillespie BM, Chaboyer W, Wallis M. Development of a theoretically derived model of resilience through concept analysis. Contemp Nurse 2007;25(1/2):124-35.

17. Van Breda AD. Resilience theory: a literature review. Pretoria (South Africa): South African Military Health Service; 2001.

18. Zauszniewski JA, Bekhet AK, Suresky MJ. Effects on resilience of women family caregivers of adults with serious mental illness: the role of positive cognitions. Arch Psychiatr Nurs 2009;23(6):412-22.

19. Pickett-Schenk SA, Cook JA, Steigman P, et al. Psychological well-being and relationship outcomes in a randomized study of family-led education. Arch Gen Psychiatry 2006;63:1043-50.

20. Stjernswärd S, Ostman M. Whose life am I living? Relatives living in the shadow of depression. Int J Soc Psychiatry 2008;54(4):358-69.

21. Pickett-Schenk SA, Cook JA, Laris A. Journey of Hope program outcomes. Community Ment Health J 2000;36:413-24.

22. Murray-Swank AB, Lucksted A, Medoff DR, et al. Religiosity, psychosocial adjustment, and subjective burden of persons who care for those with mental illness. Psychiatr Serv 2006;57(3):361-5.

23. Pipatananond $\mathrm{P}$, Boontong T, Hanucharurnkul S, et al. Caregiver burden predictive model: an empirical test among caregivers for the schizophrenic. Thai J Nurs Res 2006;6(2):24-40.

24. Fortune DG, Smith JV, Garvey K. Perceptions of psychosis, coping, appraisals, and psychological distress in the relatives of patients with schizophrenia: an exploration using self-regulation theory. Br J Clin Psychol 2005;44:319-31.

25. Perlick DA, Rosenheck RA, Miklowitz DJ, et al. Caregiver burden and health in bipolar disorder: a cluster analytic approach. J Nerv Ment Dis 2008;196(6):484-91.

26. Suresky MJ, Zauszniewski JA, Bekhet AK. Sense of coherence and quality of life in women family members of the seriously mentally ill. Issues Ment Health Nurs 2008;29:265-78.

27. Zauszniewski JA, Bekhet AK, Suresky MJ. Relationships among stress, depressive cognitions, resourcefulness and quality of life in female relatives of seriously mentally ill adults. Issues Ment Health Nurs 2009;30:142-50.

28. Wang S, Rong J, Chen C, et al. [A study of stress, learned resourcefulness and caregiver

15 Zauszniewski, Bekhet \& Suresy 
burden among primary caregivers of schizophrenic adolescents]. J Nurs 2007;54(5):37-47 [in Chinese].

29. Ungar M. A constructionist discourse on resilience: multiple contexts, multiple realities among at-risk children and youth. Youth Soc 2004;35(3):341-65.

30. Rutter M. Psychosocial resilience and protective mechanisms. Am J Orthopsychiatry 1987;57:316-31.

31. Chan SW, Yip B, Tso S, et al. Evaluation of a psychoeducation program from Chinese clients with schizophrenia and their family caregivers. Patient Educ Couns 2009;75:67-76.

32. Cheng LY, Chan SW. Psychoeducation program for Chinese family carers of members with schizophrenia. West J Nurs Res 2005;27(5):583-99.

33. Pollio DE, North CS, Osborne VA. Family-responsive psychoeducation groups for families with an adult member with mental illness: pilot results. Community Ment Health $\mathrm{J}$ 2002;38(5):413-21.

34. Zauszniewski JA, Bekhet AK, Suresky MJ. Factors associated with perceived burden, resourcefulness, and quality of life in female family members of adults with serious mental illness. J Am Psychiatr Nurses Assoc 2008;14(2):125-35.

35. Enns R, Reddon J, McDonald L. Indications of resilience among family members of people admitted to a psychiatric facility. Psychiatr Rehabil J 1999;23(2): 127-33.

36. Marsh DT, Lefley HP, Evans-Rhodes D, et al. The family experience of mental illness: evidence for resilience. Psychiatr Rehabil J 1996;20(2):3-12.

37. Mannion E. Resilience and burden in spouses of people with mental illness. Psychiatr Rehabil J 1996;20(2):13-23.

38. Orsillo SM, Roemer L, Block-Lerner J, et al. Acceptance, mindfulness, and cognitive-behavioral therapy: comparisons, contrasts and applications to anxiety. In: Hayes SC, Follette VM, Linehan MM, editors. Mindfulness and acceptance: expanding the cognitive-behavioral tradition. New York: Guilford Press; 2004. p. 66-95.

39. Sethabouppha $\mathrm{H}$, Kane C. Caring for the seriously mentally ill in Thailand: Buddhist family caregiving. Arch Psychiatr Nurs 2005;19(2):44-57.

40. Christensen A, Jacobson NS. Reconcilable differences. New York: Guilford Press; 2000.

41. Quinn N. Beliefs and community responses to mental illness in Ghana: the experiences of family carers. Int J Soc Psychiatry 2007;53(2):175-88.

42. Eisner LR, Johnson SL. An acceptance-based psychoeducation intervention to reduce expressed emotion in relatives of bipolar patients. Behav Ther 2008;39: 375-85.

16 Zauszniewski, Bekhet \& Suresy 
43. Kobasa SC. Stressful life events, personality and health: an inquiry into hardiness. J Pers Soc Psychol 1979;37:1-11.

44. Maddi SR. On hardiness and other pathways to resilience. Am Psychol 2005; 60(3):261-2.

45. DiBartolo M. Exploring self-efficacy and hardiness in spousal caregivers of individuals with dementia. J Gerontol Nurs 2002;28(4):24-33.

46. DiBartolo M, Soeken K. Appraisal, coping, hardiness, and self-perceived health in community-dwelling spouse caregivers of persons with dementia. Res Nurs Health 2003;26(6):445-58.

47. Clark P. Effects of individual and family hardiness on caregiver depression and fatigue. Res Nurs Health 2002;25(1):37-48.

48. Greef AP, Vansteenwegen A, Ide M. Resiliency in families with a member with a psychological disorder. Am J Fam Ther 2006;34:285-300.

49. Han K, Lee P, Park E, et al. Family functioning and mental illness: a Korean correlational study. Asian J Nurs 2007;10(2):129-36.

50. Pearlin LI, Schooler C. The structure of coping. J Health Soc Behav 1978;19: 2-21.

51. Rungreangkulkij S, Gillis CL. Conceptual approached to studying family care-giving for persons with severe mental illness. J Fam Nurs 2000;6(4):341-66.

52. Rose LE, Mallinson RK, Gerson LD. Mastery, burden, and areas of concern among family caregivers of mentally ill persons. Arch Psychiatr Nurs 2006; 20(1):41-51.

53. Lau D, Pang A. Caregiving experience for Chinese caregivers of persons suffering from severe mental disorders. Hong Kong J Psychiatr 2007;17:75-80.

54. Dufault K, Martocchio B. Hope: its spheres and dimensions. Nurs Clin North Am 1985;20(2):379-91.

55. Parse RR. Hope: an international human becoming perspective. Boston: Jones and Hartlett; 2000.

56. Bland R, Darlington $Y$. The nature and sources of hope: perspectives of family caregivers of people with serious mental illness. Perspect Psychiatr Care 2002; 38(2):61-8.

57. Karp DA, Tanarugsachock V. Mental illness, caregiving, and emotional management. Qual Health Res 2000;10(1):6-25.

58. Tweedell D, Forchuk C, Jewell J, et al. Families' experience during recovery or nonrecovery from psychosis. Arch Psychiatr Nurs 2004;18(1):17-25.

59. Pickett-Schenk SA, Lippincott RC, Bennett C, et al. Improving knowledge about mental illness through family-led education: the journey of hope. Psychiatr Serv 2008;59(1):49-56.

17 Zauszniewski, Bekhet \& Suresy 
60. Bandura A. Self-efficacy: the exercise of control. New York: WH Freeman; 1997.

61. Zulkosky K. Self-efficacy: a concept analysis. Nurs Forum 2009;44(2):93-102.

62. Antonovsky A. Health, stress, and coping. San Francisco (CA): Jossey-Bass; 1979.

63. Rosenbaum M. Learned resourcefulness on coping skills, self-control, and adaptive behavior. New York: Springer; 1990.

64. Nadler A. Help-seeking behavior as a coping resource. In: Rosenbaum M, editor. Learned resourcefulness: on coping skills, self-control, and adaptive behavior. New York: Springer; 1990. p. 127-64.

65. Zauszniewski JA. Resourcefulness. In: Fitzpatrick JJ, Wallace M, editors. Encyclopedia of nursing research. New York: Springer; 2006. p. 526-8.

\section{Appendix}

Table 1

Risk/vulnerability factors, protective factors, and outcomes of resilience indicators identified in studies of family members of adults with mental illness

\begin{tabular}{|c|c|c|}
\hline Risk/Vulnerability Factors & Protective/Positive Factors & $\begin{array}{l}\text { Outcomes of Resilience } \\
\text { Indicators }\end{array}$ \\
\hline $\begin{array}{l}\text { Family member with mental } \\
\text { illness }\end{array}$ & $\begin{array}{l}\text { Control appraisal }\left.\right|^{24} \\
\text { Positive appraisal }\left.\right|^{53}\end{array}$ & $\begin{array}{l}\text { Expressed emotion }{ }^{42} \\
\text { Psychological well-being }{ }^{19,24}\end{array}$ \\
\hline $\begin{array}{l}\text { Lack of mental health } \\
\text { services/support }\end{array}$ & $\begin{array}{l}\text { Personal religiosity } \\
\text { Psychoeducation }^{31-33}\end{array}$ & $\begin{array}{l}\text { Family adaptation }{ }^{48} \\
\text { Family functioning }\end{array}$ \\
\hline Threat appraisal ${ }^{24}$ & Social support ${ }^{23}$ & Knowledge and \\
\hline Caregiver age $\mathrm{e}^{22,23}$ & Positive cognitions ${ }^{18}$ & understanding 21,59 \\
\hline Education 23 & Length of time since & Morale 21 \\
\hline $\begin{array}{l}\text { Caregiver burden/ } \\
\text { stress }^{25-27}\end{array}$ & $\begin{array}{l}\text { diagnosis } \\
\text { Age of care recipient }{ }^{34}\end{array}$ & $\begin{array}{l}\text { Relationship to mentally ill } \\
\text { person }{ }^{19}\end{array}$ \\
\hline Caregiver strain ${ }^{27}$ & & Caregiver burden ${ }^{23,28}$ \\
\hline Family disruption ${ }^{27}$ & & Quality of life $e^{26,27}$ \\
\hline $\begin{array}{l}\text { Stressful life events } \\
\text { Avoidance coning } \\
25\end{array}$ & & \\
\hline Avoidance copin & & \\
\hline
\end{tabular}

